\title{
Successful en bloc resection with acceptable cosmesis of a right recurrent giant scalp-orbital AVM causing severe disfigurement: a
} case report

\author{
Anjan Singh Karki, Dipendra Kumar Shrestha, Gopal Sedain, Sushil Krishna Shilpakar
}

\section{Abstract}

Scalp arteriovenous malformation (AVM) accounts for only $8.1 \%$ of all AVM cases. These lesions are made up of an abnormal fistulous tangle of tortuous dysmorphic network of vessels "vascular nidus" directly connecting between the feeding arteries and draining veins, without capillary connection, located within the incision subcutaneous layer.

With time, these congenital lesions may evolve and enlarge and clinically manifest with variable features. The only effective method of preventing evolution of these malformations is to exclude the lesion completely from the circulation. Involvement of the orbit and face may cause severe facial disfigurement, proptosis, visual obstruction and even facial palsy. These lesions may be complicated by ulceration, infection and profuse bleeding.

We present a rare case of 40 -year-old female with a recurrent congenital scalp-orbital AVM causing proptosis, visual obstruction on the right eye with severe facial disfigurement. The lesion was successfully excised with acceptable cosmesis and removal of the visual obstruction. A brief literature review, imaging findings and the surgical techniques have been presented.

Keywords: Arteriovenous malformation; disfigurement; en bloc resection; proptosis; scalp-orbital.

\section{Introduction}

Scalp arteriovenous malformation (AVM) is a rare congenital entity, accounting for only $8.1 \%$ of all AVM cases. ${ }^{1}$ Generally, scalp AVM presents as a small pulsatile mass; but with time, if untreated, it will progressively enlarge and spread to the entire scalp, giving a grotesque appearance and involves the craniofacial structures and skull bone and even extends intracranially, leading to seizures and hemorrhages.

There are varieties of neuro-imaging modalities which help in characterizing the structural complexity, location and the extent of the lesion and assist in appropriate preoperative surgical planning. Among them, three-dimensional CT angiography (3D-CTA) is regarded as the cornerstone for investigation.

\section{Author affiliations:}

Department of Neurosurgery Tribhuvan University Teaching Hospital, Maharajgunj Medical Campus, Maharajgunj, Kathmandu, Nepal.

\section{Correspondence:}

Dr. Anjan Singh Karki, Department of Neurosurgery Tribhuvan University Teaching Hospital, Maharajgunj Medical Campus, Institute of Medicine, PO Box 3579, Maharajgunj, Kathmandu, Nepal.

Email: dranjansinghkarki@gmail.com

ORCID iD:

https://orcid.org/0000-0001-7431-5898

Copyright information:

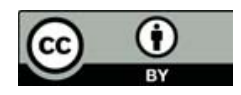

How to cite this article:

Karki AS, Shrestha DK, Sedain G, Shilpakar SK. Successful en bloc resection with acceptable cosmesis of a right recurrent giant scalp-orbital AVM causing severe disfigurement: a case report. J Soc Surg Nep. 2021 Jul;24(1):28-33.

DOI:

https://doi.org/10.3126/jssn.v24i1.41003
Management of these complex lesions may require multidisciplinary approach with preoperative embolization and surgical excision. As it is often difficult to cure scalp AVM with embolization alone, surgical resection is usually required. Generally, surgical excision is said to be curative; and recurrence is uncommon after complete resection.

\section{Case report}

A 40-year-old housewife, from Western Nepal, presented to our Neurosurgical Out-patient Clinic with a large pulsatile grotesque mass over the right fronto-orbital region. She was very depressed; and she had visited numerous hospitals to have this lesion removed so that she could see with her right eye and get rid of the noticeable facial disfigurement. She was born with a swelling in the right frontotemporal region, which over time increased in size progressively. 
The pulsatile lesion was excised; and the scalp defect was reconstructed with full-thickness skin graft in April of 1992 in a different hospital in Nepal. Later, a small swelling recurred over the right supraorbital region, located anterior to the previous surgical site, which gradually increased in size over the last two years. This led to proptosis of the right eye as well as visual obstruction finally leading to severe facial disfigurement. However, there was no pain, discharge, ulceration or bleeding from the lesion.

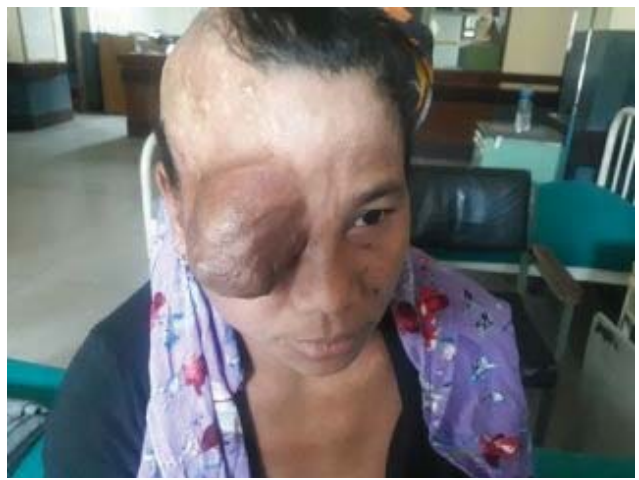

Figure 1. Preoperative picture showing the giant highflow scalp-orbital AVM causing visual obstruction of the right eye and severe facial disfigurement. Note the right frontotemporal bald area due to previous skin graft and incisional scar.

On physical examination, she was fairly-built with darker skin complex. Vital signs were stable. Right frontotemporal region was bald with glistening skin due to previous skin graft. An oblong healthy incisional scar was noted surrounding the $10 \times 6 \mathrm{~cm} 2$ grafted hairless area. There was approximately 7 x 5 x $5 \mathrm{~cm} 3$ soft to firm spherical nontender pulsatile mass with engorged superficial vessels on overlying the coarse hyperpigmented skin arising from the right orbital region (Figure 1).

On auscultation, bruit was heard clearly over the lesion. The patient was unable to open her right eye due to the large mass; and the right eyeball was displaced downward. However, the horizontal movement of the right eye was intact. Both pupils were round, regular and reactive to

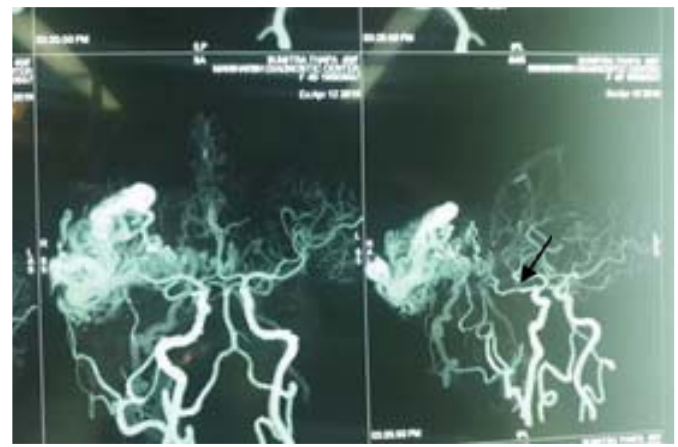

Figure 2. CT angiography demonstrating large vascular nidus with multiple arteries feeders, predominantly supplied by right ophthalmic artery (black arrow).

light. Visual acuity on both eyes was 6/9. Examination of all other systems was normal.

On neuroradiological evaluation, CT angiography of head demonstrated an extensive vascular nidus within the swollen soft tissue of right periorbital and inferior frontal region. The lesion was supplied by numerous feeding arteries, namely frontal, supratrochlear, supraorbital branches of the right superficial temporal artery, angular branches of both facial arteries; and the major feeder was from the intracranial circulation via right ophthalmic artery.

Three-dimensional images (3D-CTA) revealed large highly vascular nidus involving predominantly the right forehead on supraorbital region and extending into the orbital region without involvement of skull or intracranial structures (Figure 2, Figure 3).

The diagnosis was consistent with recurrent high-flow scalp-orbital AVM. She underwent surgical excision of AVM and superior eyelid repair under general anesthesia in May of 2019. Before making the incision, temporary occlusion of major dilated feeding arteries was performed by ligating them percutaneously with 3-0 silk suture, approximately $2 \mathrm{~cm}$ proximal to the planned excisional margin. Notably dilated anterior (frontal), supratrochlear and supraorbital branches of the right superficial temporal
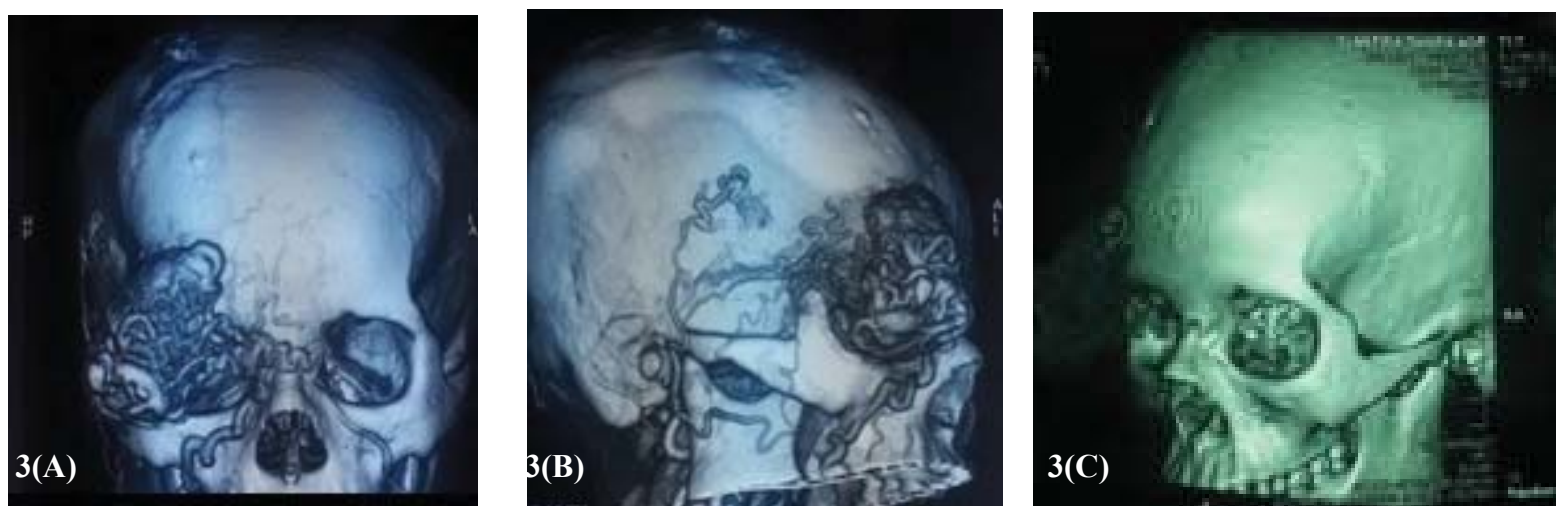

Figure 3. Three-dimensional CT angiography (3D-CTA) showing the giant right scalp-orbital AVM in relation to the skull and orbit (A) anterior, (B) lateral and (C) oblique views. Note the extension of lesion into the orbit without involvement skull bone and without intracranial extension. 
artery lying superiorly and right and left angular arteries located inferior-medially, supplying the pulsatile mass were ligated to reduce the blood flow to the lesion and decrease blood loss during dissection and excision of the vascular mass. A curvilinear incision was made along middle aspect of the globular swelling inferior to the presumed right eyebrow. Meticulous dissection and thorough hemostasis were maintained using monopolar and bipolar coagulation. The dissection was initiated from the normal-looking tissue over the superior aspect of vascular nidus. Using monopolar Bovie cautery, the pericranium and frontalis muscle on the superior margin of the lesion were delineated and dissected off the frontal bone. The bony surface was thoroughly waxed and electrocauterized to stop the oozing blood. The large dilated vessels were dissected and individually ligated with 3-0 silk sutures. The lesion was circumferentially dissected and excess skin was also excised. Utmost care was taken to avoid injury to the lacrimal gland and levator and orbicularis muscles. Laterally, the zygomatic branch and the main stump and non-dilated normal branches of superficial temporal artery were carefully preserved so as not to jeopardize vascularity of the previously grafted scalp. After circumferential excision, the lesion was still attached to the vascular pedicle involving the orbit. Within the pedicle, the distal part of right superior ophthalmic artery was identified and doubly-ligated separately. Finally, the lesion with the entire vascular nidus was completely removed via en bloc resection. Hemostasis was strictly secured using monopolar and bipolar cauterization. The excess skin over the superior eyelid was removed; and

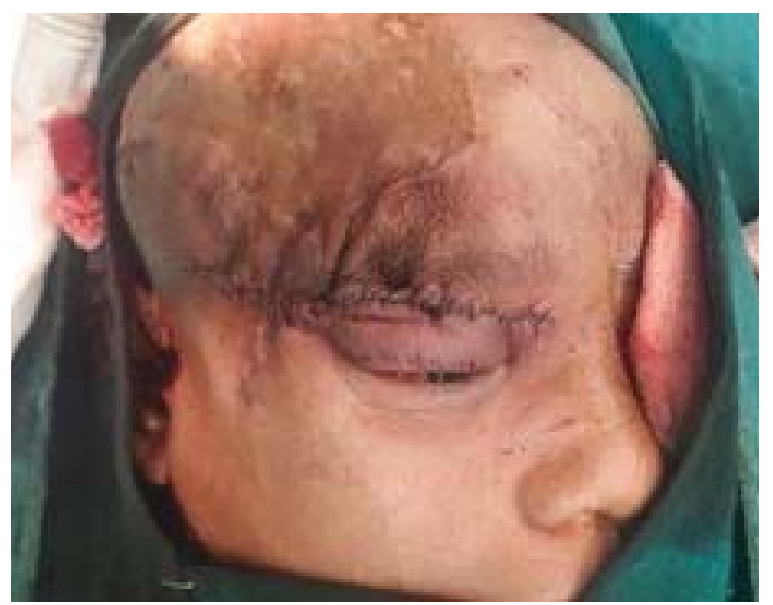

Figure 4. Postoperative picture showing curvilinear incision below the right eyebrow and acceptable cosmesis after excision of right scalp-orbital AVM.

incision was reconstructed for acceptable aesthetic and cosmesis. The incision was then closed in layers: musclefascia with 3-0 vicryl interruptedly and skin with 4-0 prolene continuously. No drain was placed (Figure 4).

Macroscopic examination demonstrated a single piece of grey-brown skin tissue grey, measuring 7.5 x $5 \mathrm{~cm}$. The cut section showed multiple dilated vessels containing clot and pinpoint hemorrhagic areas. Microscopic view revealed multiple variable-sized interlacing vascular spaces in fat and soft tissues. Some of the vessels were lined by endothelial cells. However, other vascular spaces showed elastic and muscular layers as well as arteries and veins. Nerve bundles were also intermixed. The findings were consistent with AVM of supraorbital region.

Though there was mild periorbital swelling post-surgery which eventually subsided, the postoperative course was largely uneventful. The patient was discharged on postoperative day four. Sutures were removed on POD\#10 in the Out-patient Clinic. On one-month follow up, the patient was high-spirited. She was finally able to see well, look up and close her right eye after two long agonizing years. The incision healed with secondary intention with patchy area of dark discolored indurated skin on the upper lateral aspect of the incision.

Though some patchy areas of skin necrosis, requiring no revision, were noted during one-month follow-up visit, there were no major postoperative complications, namely infection, dehiscence or bleeding. The final result was an acceptable cosmesis without visual obstruction and correction of severe facial disfigurement caused by the giant pulsatile mass (Figure 5).
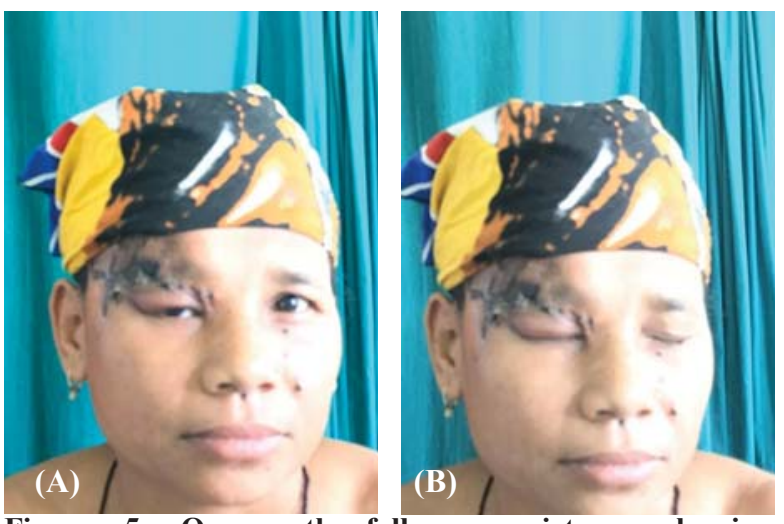

Figure 5. One-month follow-up pictures showing elated patient after complete excision of mass with right supraorbital incisional scar with patchy areas of hyperpigmentation and skin necrosis. She is able to (A) open and (B) close her right eye.

\section{Discussion}

Scalp-orbital AVMs are rare congenital entities, which may have variable clinical pictures. Extensive lesions may cause ulceration, profuse bleeding and disfigurement and recurrence even after excision. In our case, the patient had undergone extensive excision with skin graft 10 years back; but the lesion had recurred and extended into the right orbital region causing visual obstruction and severe facial disfigurement. However, there was no skin ulceration or bleeding.

Over the last two decades, the reports of scalp AVM has increased significantly; and this is most likely due to 
improved diagnostic tools. In history, due to its unusual portly appearance, various nomenclature has been used to describe these lesions, including aneurysm cirsoides, racemose aneurysm, plexiform angioma, pulsating angioma, scalp arteriovenous fistula, arteriovenous aneurysm, aneurysmal varicose and arteriovenous malformations. ${ }^{2-4}$

There is still ongoing controversy regarding clear-cut etiology of scalp AVM. It maybe congenital, traumatic, ${ }^{5-12}$ infectious, inflammatory and idiopathic. ${ }^{13-19}$ Most authors accept that it is caused by penetrating or blunt trauma; ${ }^{20,21}$ ) some are congenital (spontaneous); ${ }^{.22,23}$ while few can be iatrogenic such as due to craniotomy, hair transplantation ${ }^{24-27}$ or even intravenous scalp infusion. Congenital scalp AVM may present at birth; but, in majority, it remains asymptomatic until adulthood, ${ }^{3,20,28}$ similar to our case.

Based on the extent of the blood flow, scalp AVM can be divided into low-flow or high-flow AVM. The lowflow lesions are usually well-demarcated, which include cavernoma, cavernous hemangioma, venous malformation and sinus pericranii, can easily be diagnosed with MRI and are treatable by sclerotherapy or embolization alone. On the other hand, high-flow AVMs are large and extensive, producing loud bruit $^{6}$ heard on auscultation, containing multiple feeding and draining vessels and frequently requiring surgical excision. They may even reduce cerebral blood flow causing so-called "steal" phenomenon. ${ }^{29}$

In their study, Shenoy and colleagues ${ }^{20}$ classified these scalp AVM into two groups based on their angiographic features: group I: the primary scalp AVM and group II: secondary venous dilatations. In the primary scalp AVM, the arterial feeders arise from the calvarial branches of the external carotid arteries, ophthalmic arteries and vertebral arteries while the draining veins enter into the scalp venous system. In group II, the dilated channels are the main outflow vessels of the intracranial vascular malformations. Accordingly, our case belonged to group I.

Regarding anatomical location, scalp AVM are roughly evenly distributed located in the frontal, temporal and parietal regions. ${ }^{30}$ Generally, the major feeding vessels are located in the subcutaneous layer of the scalp, often originating from external carotid, occipital and supraorbital arteries. ${ }^{31}$ Frequently, STA is involved in traumatic cirsoid aneurysm due to its long unprotected course. ${ }^{31-33}$ In our case, being a high-flow AVM, it had multiple feeders, including from anterior, supratrochlear, supraorbital branches of STA and angular branches from both facial arteries. However, major feeder was from the right ophthalmic artery intraorbitally.

The clinical manifestation of AVM is highly variable, presenting with small pulsatile mass to extensive craniofacial disfigurement and grotesque appearance, producing throbbing headache, localized pain, proptosis, visual hindrance, epistaxis, tinnitus, numbness, necrosis, ulceration or hemorrhage. . $^{2,31,33,34}$
In regards to the optimum management of such lesion, it may be quite complicated due to various factors such as the highly complex vascular anatomy, large collateral link, high-flow rate, massive blood loss, intracranial and facial involvement causing cosmetic and neurological problems after surgical intervention. The aim of treatment should be to completely eliminate the lesion from the normal scalp circulation. These lesions are generally diagnosed based on clinical observation as most are quite noticeable.

Recently, spectra of neuro-imaging modalities are available for diagnosing this pathology, to know the extent and complexity of the lesion and to understand the arterial feeders of the vascular nidus and to decide the best treatment strategy. These include plain and contrast Computerized Tomography (CT), three-dimensional CT angiography (3D-CTA), conventional extracranial and intracranial angiography, digital subtraction angiography (DSA), cranial doppler and Magnetic resonance imaging (MRI). Among them, angiography is considered as the gold standard of investigation to delineate the lesion, to understand its angioarchitecture and to exclude any intracranial component. ${ }^{8}$ It is of great importance for diagnosis and treatment selection and particularly employed for the determining main cranial feeders. On the other hand, MRI of brain shows flow void signs due to rapid flow in the lesion $^{3,8,16,35}$ and is significant in establishing the diagnosis. In our case, we were able to obtain 3D-CTA which was able to clearly demonstrate the extent of the lesion and the multiple arterial feeders, making it possible for proper preoperative surgical planning.

Generally, this is a complex disease requiring multidisciplinary approach. In regards to treatment options for craniofacial AVM, there are numerous modalities, which include direct ligation of supplying vessels, extensive surgical excision, ${ }^{4,23,36-38}$ embolization via transarterial and transvenous routes, ${ }^{6,20,30,37}$ percutaneous intralesional injection of sclerosant ${ }^{36,37}$ and electro-thrombosis. ${ }^{39,40}$ Conventionally, the most common modality and treatment of choice that is curative is still the surgical excision. . $^{13,16,20}$ However, with new advents, endovascular approach by itself or combination with surgery has been recommended for these complex malformations..$^{41,42}$

Variety of agents have been applied for pre or intraoperative embolization of these lesions, which include boiling water, absolute alcohol, gelfoam pledgets, fibrin glue, thrombin, platinum coils, cyanoacrylate, sclerosant and onyx. ${ }^{43}$

There are numerous innovative techniques to reduce bleeding during surgery, which includes percutaneous suturing of the feeding vessels,${ }^{20}$ interlock-suturing along the incisional margin and tamponading with tourniquet, making stepwise incision with manual digital pressure and compressing the flap with intestinal clamp. ${ }^{31}$ In our case, we applied the percutaneous technique of suturing to gain proximal vascular control prior to incision. 
Due to the abnormal fistulous communication, AVM must be completely eliminated because recurrence or enlargement is reported after an incomplete resection; $;^{36}$ )so, emphasis should be given to en bloc resection of the vascular nidus and tight ligation of all the feeders to prevent recurrence. Recurrence has been reported as late as 18 years after surgical resection. ${ }^{5}$ In our case, the lesion seems to have recurred after 8 years. After surgical excision, common postoperative complications include wound infection, sepsis, recurrence, hemorrhage and scalp necrosis. $3,4,8,16$ Except for some patchy area of skin necrosis, none of other complications occurred in our case.

In our case, we did not apply preoperative embolization due to the involvement of right orbit rather we were able

\section{References}

1. Worm PV, Ruschel LG, Roxo MR, Camelo R. Giant scalp arteriovenous malformation. Rev Assoc Med Bras (1992). 2016 Dec;62(9):828-30.

2. Khodadad G. Arteriovenous malformations of the scalp. Ann Surg. 1973 Jan;177(1):79-85.

3. Fisher-Jeffes ND, Domingo $Z$, Madden $M$, de Villiers JC. Arteriovenous malformations of the scalp. Neurosurgery. 1995 Apr;36(4):656-60.

4. Muthukumar N, Rajagopal V, Manoharan AV, Durairaj N. Surgical management of cirsoid aneurysms. Acta Neurochir (Wien). 2002 Apr;144(4):349-56.

5. Wilkinson HA. Recurrence of vascular malformation of the scalp 18 years following excision. Case report. J Neurosurg. 1971 Mar;34(3):435-7.

6. Barnwell SL, Halbach VV, Dowd CF, Higashida RT, Hieshima GB. Endovascular treatment of scalp arteriovenous fistulas associated with a large varix. Radiology. 1989 Nov;173(2):533-9.

7. Lanzino G, Passacantilli E, Lemole GM Jr, McDougall C, Spetzler RF. Scalp arteriovenous malformation draining into the superior sagittal sinus associated with an intracranial arteriovenous malformation: just a coincidence? Case report. Neurosurgery. 2003 Feb;52(2):440-3.

8. Matsushige T, Kiya K, Satoh H, Mizoue T, Kagawa $\mathrm{K}$, Araki H. Arteriovenous malformation of the scalp: case report and review of the literature. Surg Neurol. 2004 Sep;62(3):253-9.

9. El Shazly AA, Saoud KM. Results of surgical excision of cirsoid aneurysm of the scalp without preoperative interventions. Asian J Neurosurg. 2012 Oct;7(4):191-6.

10. Nishijima I, Ikemura R, Gushiken M, Miyagi K, Iha K. Nonsurgical treatment of scalp arteriovenous malformation using a combination of ultrasoundguided thrombin injection and transarterial coil embolization. J Vasc Surg. 2012 Mar;55(3):833-6.

11. Dmytriw AA, Ter Brugge KG, Krings T, Agid to attain proximal control by ligating the major arterial feeders percutaneously and eventually excising the lesion completely in toto with minimal blood loss.

\section{Conclusion}

Scalp-orbital AVM is a rare entity which may cause proptosis, visual obstruction and severe long-standing facial disfigurement as in our case. With appropriate planning prior to surgery, proximal control of feeding arteries just before incision and complete removal of lesion in toto, large high-flow scalp-orbital AVM can be excised safely without any major complications and with acceptable cosmesis.

R. Endovascular treatment of head and neck arteriovenous malformations. Neuroradiology. 2014 Mar;56(3):227-36.

12. Munakomi S, Bhattarai B, Cherian I. Conquering the odds: Cirsoid aneurysm with holocranial feedersstaged embolization, excision and grafting. Asian J Neurosurg. 2015 Jul-Sep;10(3):259-61.

13. Hendrix LE, Meyer GA, Erickson SJ. Cirsoid aneurysm treatment by percutaneous injection of sodium tetradecyl sulfate. Surg Neurol. 1996 Dec;46(6):557-60.

14. Hage ZA, Few JW, Surdell DL, Adel JG, Batjer $\mathrm{HH}$, Bendok BR. Modern endovascular and aesthetic surgery techniques to treat arteriovenous malformations of the scalp: case illustration. Surg Neurol. 2008 Aug;70(2):198-203.

15. Godwin O, Ayotunde O, Millicent O, Yvonne O: Extracranial arteriovenous malformation of thescalp: value of computed tomographic angiography. The Internet Journal of Radiology 2006;5:1.

16. Senoglu M, Yasim A, Gokce M, Senoglu N. Nontraumatic scalp arteriovenous fistula in an adult: technical report on an illustrative case. Surg Neurol. 2008 Aug;70(2):194-7.

17. Chowdhury FH, Haque MR, Kawsar KA, Sarker MH, Momtazul Haque AF. Surgical management of scalp arterio-venous malformation and scalp venous malformation: An experience of eleven cases. Indian J Plast Surg. 2013 Jan;46(1):98-107.

18. Raheja A, Satyarthee GD, Sharma BS. Single, small, spontaneous, accessory, closed type, frontal sinus pericranii in a child: favorable outcome with surgical excision. Neurol India. 2013 Nov-Dec;61(6):680-3.

19. Rane SY, Lamba S, Gohil AJ, Gupta AK. Compendium of scalp arteriovenous malformation (AVM) cases - a retrospective study and review. European Journal of Plastic Surgery 2017;41:223-8.

20. Shenoy SN, Raja A. Scalp arteriovenous malformations. Neurol India. 2004 Dec;52(4):47881.

21. Massimi L, De Bonis P, Esposito G, Novegno F, Pettorini B, Tamburrini G, Caldarelli M, Di Rocco 
C. Vertex scalp mass as presenting sign of a complex intracranial vascular malformation. J Neurosurg Pediatr. 2009 Apr;3(4):307-10.

22. Schultz RC, Hermosillo CX. Congenital arteriovenous malformation of the face and scalp. Plast Reconstr Surg [Internet]. 1980;65(4).

23. Domingo Z, Fisher-Jeffes ND, de Villiers JC. Surgical management of arteriovenous malformations of the scalp. In: Shmidek HN, editor. Operative Neurosurgical Techniques: Indications, Methods and Results. 4th ed. Philadelphia: Saunders Company; 2000. pp. 1331-1338.

24. Souder DE, Bercaw BL. Arteriovenous fistula secondary to hair transplantation. N Engl J Med. 1970 Aug 27;283(9):473-4.

25. Barros d'Sa AA, Heard CE. Arteriovenous fistula after hair transplantation. Br Med J. 1978 Feb 11;1(6109):340-1.

26. Lanzieri CF, Sacher M, Som PM, Haimov M. Arteriovenous fistula after hair transplantation. AJNR Am J Neuroradiol. 1985 Jan-Feb;6(1):111-2.

27. Liounakos JI, Urakov T, Snelling B, Peterson EC. Scalp arteriovenous fistula following hair transplantation: acase Report and review of the literature. Clin Med Rev Case Rep. 2018;5:200.

28. Li F, Zhu S, Liu Y, Chen Y, Chi L, Chen G, Zhang J, Qu F. Traumatic arteriovenous fistula of the superficial temporal artery. J Clin Neurosci. 2007 Jun;14(6):595-600.

29. Mast H, Mohr JP, Osipov A, Pile-Spellman J, Marshall RS, Lazar RM, Stein BM, Young WL. 'Steal' is an unestablished mechanism for the clinical presentation of cerebral arteriovenous malformations. Stroke. 1995 Jul;26(7):1215-20.

30. Kasdon DL, Altemus LR, Stein BM. Embolization of a traumatic arteriovenous fistula of the scalp with radiopaque Gelfoam pledgets. Case report and technical note. J Neurosurg. 1976 Jun;44(6):753-6.

31. Hochberg J, Ardenghy M, Pait TG. Scalp tourniquet. Br J Plast Surg. 1994 Apr;47(3):194-8.

32. Gupta AK, Purkayastha S, Bodhey NK, Kapilamoorthy TR, Krishnamoorthy T, Kesavadas C, Thomas B. Endovascular treatment of scalp cirsoid aneurysms. Neurol India. 2008 AprJun;56(2):167-72.

33. Burrus TM, Miller GM, Flynn LP, Fulgham JR, Lanzino G. NeuroImages. Symptomatic left temporal arteriovenous traumatic fistula. Neurology.
2009 Aug 18;73(7):570.

34. Manuel AM, Kalimuthu S, Pathmanathan SS, Narayanan P, Zainal Abidin Z, Azmi K, Khalil A. Challenges in the management of massive intraorbital and hemifacial arteriovenous malformation as causing life-threatening epistaxis. Asian J Surg. 2017 Apr;40(2):158-62.

35. Hasturk AE, Erten F, Ayata T. Giant non-traumatic arteriovenous malformation of the scalp. Asian J Neurosurg. 2012 Jan;7(1):39-41.

36. Shepard RH. Proceedings: Cirsoid arteriovenous malformations of the scalp. J Neurol Neurosurg Psychiatry. 1975 Aug;38(8):827-8.

37. Nagasaka S, Fukushima T, Goto K, Ohjimi H, Iwabuchi S, Maehara F. Treatment of scalp arteriovenous malformation. Neurosurgery. 1996 Apr;38(4):671-7.

38. Weinzweig N, Chin G, Polley J, CharbelF, Shownkeen H, Debrun G. Arteriovenous malformation of the forehead, anterior scalp, and nasal dorsum. Plast Reconstr Surg. 2000 Jun;105(7):2433-9.

39. Gardner AM, Stewart IA. Treatment of arteriovenous malformation by endarterial electrocoagulation. Br J Surg. 1972 Feb;59(2):146-8.

40. Heilman CB, Kwan ES, Klucznik RP, Cohen AR. Elimination of a cirsoid aneurysm of the scalp by direct percutaneous embolization with thrombogenic coils. Case report. J Neurosurg. 1990 Aug;73(2):296300.

41. Komiyama M, Nishikawa M, Kitano S, Sakamoto H, Imai K, Tsujiguchi K, Mizuno T. Non-traumatic arteriovenous fistulas of the scalp treated by a combination of embolization and surgical removal. Neurol Med Chir (Tokyo). 1996 Mar;36(3):162-5.

42. Tanaka T, Hasegawa Y, Kanki T, Hayashi J, Ui K, Usami S, Abe T. [Combination of intravascular surgery and surgical operation for occipital subcutaneous arteriovenous fistula in a patient with neurofibromatosis type I]. No Shinkei Geka. 2002 Mar;30(3):309-13. [Article in Japanese].

43. Cognard C, Januel AC, Silva NA Jr, Tall P. Endovascular treatment of intracranial dural arteriovenous fistulas with cortical venous drainage: new management using Onyx. AJNR Am J Neuroradiol. 2008 Feb;29(2):235-41. 